\section{Multi-objective Optimization Using Neural Network, Differential Evolution, and Teaching Learning Based Optimization in Drilling Process of Glass Fiber Reinforced Polymer}

\author{
Kirana Alif Fatika, Mohammad Khoirul Effendi * \\ Department of Mechanical Engineering, Institut Teknologi Sepuluh Nopember, Surabaya 60111, Indonesia \\ Received: 19 August 2021, Revised: 16 September 2021, Accepted: 24 September 2021
}

\begin{abstract}
This experiment focused on the drilling process of Glass Fiber Reinforced Polymer (GFRP) composites. The data was obtained from an experiment carried out by Production Engineering Laboratory, Mechanical Engineering Department, Faculty of Industrial Technology and Systems Engineering, Institut Sepuluh Nopember Surabaya in 2019. The experiment was done with an artificial intelligence method called Backpropagation Neural Network (BPNN) as an approach to predict the response parameters (thrust force, torque, hole roundness, and hole surface roughness). The parameter inputs are drill point geometry, drill point angle, feed rate, and spindle speed. Hence the prediction would be used to gain the minimum input parameters by applying metaheuristic methods called Differential Evolution (DE) and Teaching Learning Based Optimization (TLBO). Then the result from both methods was compared to determine which method gained the better optimization values. Since BPNN-DE and BPNN-TLBO with type $\mathrm{X}$ drill point geometry was considerably better than type $\mathrm{S}$ drill point geometry, type $\mathrm{X}$ drill point geometry could be used to optimize the drilling process of GFRP.

Keywords: Drilling, backpropagation neural network, differential evolution, glass fiber reinforced polymer, teaching learning based optimization
\end{abstract}

\section{Introduction}

Glass Fiber Reinforced Polymer (GFRP) is one type of polymer that has been widely used in building blocks, electrical equipment, automotive, and aerospace industries [1-4]. The popularity of GFRP applications is aligned with its characteristics. Based on an experiment about comparison of GFRP with steel slab in building a bridge, the result shows that GFRP can bear tension much better than steel slab then considered as a strong material with a tensile strength of nearly $700 \mathrm{MPa}$ [1]. Other than that, GFRP is also classified as a light material for having a density of $1.2-2.1 \mathrm{~g} / \mathrm{cm} 3$ as stated in a catalogue published by American Concrete Institute (ACI) in 2008 [5]. Another research says that GFRP has good durability; nevertheless, it depends on several things such as temperature, humidity, whether the material is radiated by the sun, and acidic or base conditions [5,6]. By the time, the usage of GFRP will keep increasing, and it will lead to applying machining processes to GFRP. One of the processes is called drilling.

Drilling is a machining process that is used to create a circular hole using a twist drill. Its movements will produce forces in the axial direction called thrust force, and in the rotational direction called torque then these forces will affect the hole roundness and surface roughness which can influence the quality of the product [7,8]. To predict the values of these parameters, it is adequate to apply neural networks, especially the one namely Backpropagation Neural Network (BPNN) [9-12]. After obtaining the best network to gain the parameters, it is necessary to find the optimum values of these parameters. One of the methods to do that is called metaheuristic. There are some studies in optimization applying metaheuristic methods such as Differential Evolution (DE), Teaching Learning Based Optimization (TLBO), Genetic Algorithm (GA), Particle Swarm Optimization (PSO), Response Surface Methodology (RSM), Harmony Search (HS), and others [8, 13-19]. Some scholars have proposed the optimization in the drilling process of GFRP using some metaheuristics methods. However, there are not many attempts in optimizing the drilling process of GFRP using TLBO, even more using DE. Therefore, in this study, BPNN was applied together with metaheuristics, specifically DE and TLBO to predict parameter input for obtaining optimum response in drilling as shown in Figure 1. Firstly, choosing the appropriate BPNN parameters to obtain the smallest error in predicted responses. Moreover, selecting the suitable parameters in the drilling of GFRP using BPNN-DE and BPNN-TLBO to gain multi-performance response variables.

The significance of the input parameters to the output responses can be specified as follows,

"Corresponding author. Email: khoirul_effendi@me.its.ac.id 


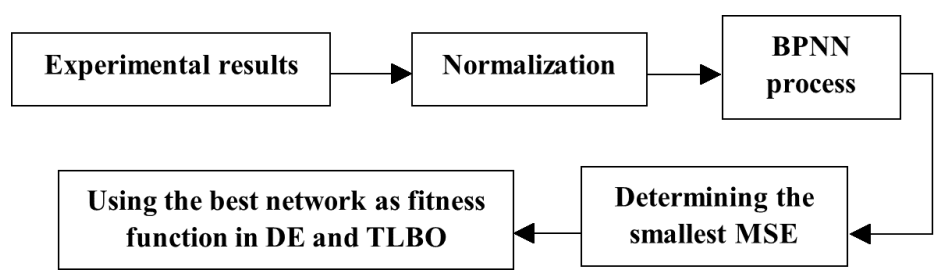

Figure 1. Steps for optimizing using BPNN-DE and BPNN-TLBO.

- Drill point geometry (PG) has influence on the values of thrust force, torque, hole roundness, and hole surface roughness. PG has various shapes such as standart-point drill bit, split-point drill bit, four-facet drill point, and splot point with double margin with different characteristics and is used to process a particular material for each shape. Choosing the right PG can affect the delamination action in the drilling process of GFRP and is related to both hole roundness and hole surface roughness of the workpiece [20,21].

- The values of drill point angle (PA) can affect the values of thrust force, torque, hole roundness, and hole surface roughness. The PA values can be $90^{\circ}$, $118^{\circ}$, or $135^{\circ}$. Each value is applied to a different material with $118^{\circ}$ being the standard PA for drilling process, $90^{\circ}$ is used for a softer material, while $135^{\circ}$ is used for a harder material [22,23].

- Increasing the value of feed rate $(f r)$ will raise the value of thrust force received by the workpiece and it can also make the torque turn bigger, while decreasing the $f r$ will have the thrust force and also torque have small values. This happens because with the low $f r$, the thickness of uncut chip thickness will be small and the relief angle will increase, it can cause the thrust force working on the workpiece to decrease. And in order to gain a low value of torque, the $f r$ needs to be set on a small value to minimize the cross-section of the chips and the effective clearance angle will increase [24,25].

- The values of spindle speed $(n)$ has influence on the numbers of thrust force, torque, hole roundness, and hole surface roughness. Increasing the values of $n$ can reduce the thrust force and torque, while decreasing the values of $n$ will enlarge the thrust force and torque working on the workpiece [24, 25].

\subsection{Drilling in GFRP}

Gurumukh Das and Padam Das [7] defined the cutting forces in the drilling process. The force acting on both the lips of a drill in drilling process may be resolved into three mutually perpendicular force components: axial force $\left(F_{A}\right)$ along the axis of a drill, radial force $\left(F_{R}\right)$ along the radial direction of a drill, and tangential force $\left(F_{T}\right)$ perpendicular to the force components $F_{A}$ and $F_{R}$ as shown in Figure 2 [26].

Since drilling is used in making hole operations and for joining the mechanical fasteners such as rivets, screws, and bolts, the delamination happening in the drilling process of FRP becomes a critical thing to be considered. Soepangkat et al. [13] stated that the delamination worked in the FRP drilling process was divided into two parts. The peel-up delamination referred to the delamination in the hole entry. In contrast, the push-out delamination referred to the exit plane, as shown in Figure 3 .

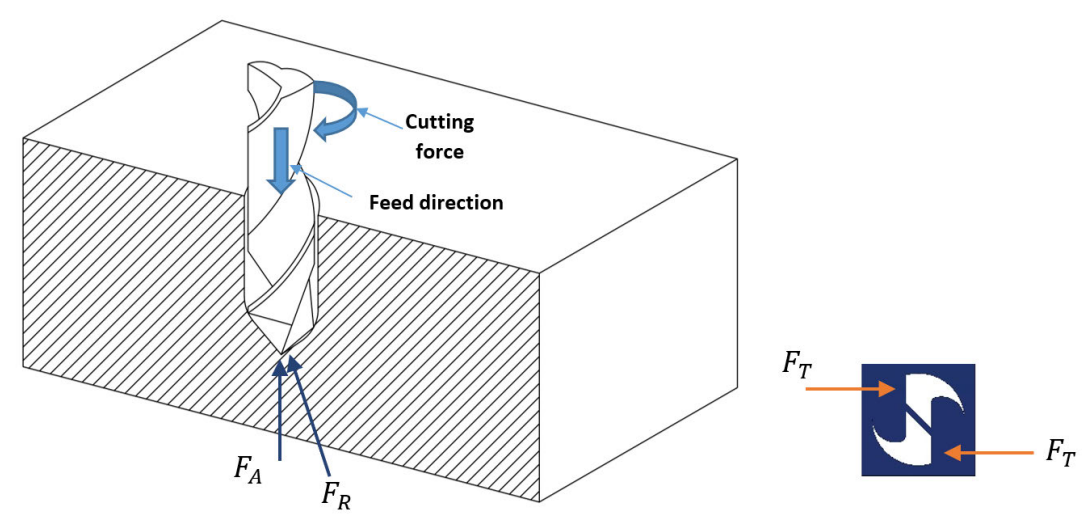

(a)

(b)

Figure 2. Forces in drilling process, (a) ISO view, (b) bottom view. 

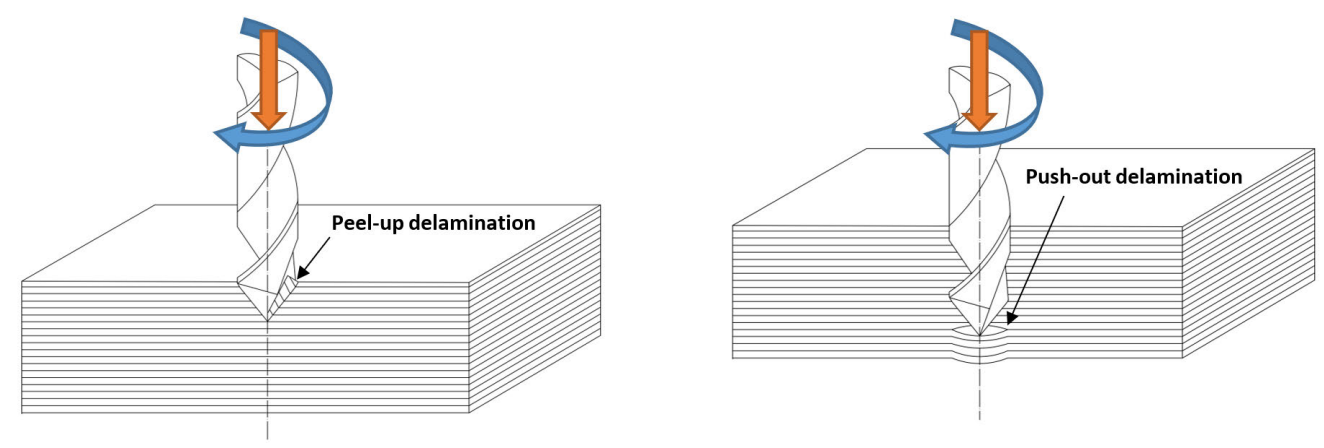

Figure 3. Delamination in drilling of GFRP.

Kumar et al. [27] explained that delamination happened because of the contact between the composite layer and the drill bit cutting edge in the axial direction through the drill flute. It results in the composite material rotating upward. It causes the composite layer to be separated from the uncut part then it is called the peel-up delamination. While the push-out delamination happens as the drill bit reaches the exit plane of the composite laminates. The uncut FRP thickness gets thinner as the drill bit gets closer to the bottom of the FRP layers hence it decreases the deformation resistance. Until a certain point, the thrust force damages the interlaminar bond strength and creates a crack. The uncut FRP layers are bent down due to this thrust force from the drill bit, and it can cause a hole exit delamination as the drill bit goes through the exit side. This delamination at the exit occurs before the FRP laminate is entirely pierced by the drill bit.
Prachad and Shaitanya [9] explained that delamination happening in the entry and exit hole of the composite layer is represented as delamination factor, which can be calculated as the ratio between the maximum diameter in the delamination area and the nominal diameter of the drill. The delamination is formulated by the following equation:

$$
D=\frac{D_{\max }}{D_{\circ}}
$$

\subsection{Drilling in GFRP}

Artificial neural network models human brain system called neural system. It consists of essential parts, namely neurons, dendrites, axons, and the connection of the neurons, as shown in Figure 4 [10]. In contrast, neural networks consist of similar parts, as shown in Figure $5[11]$.

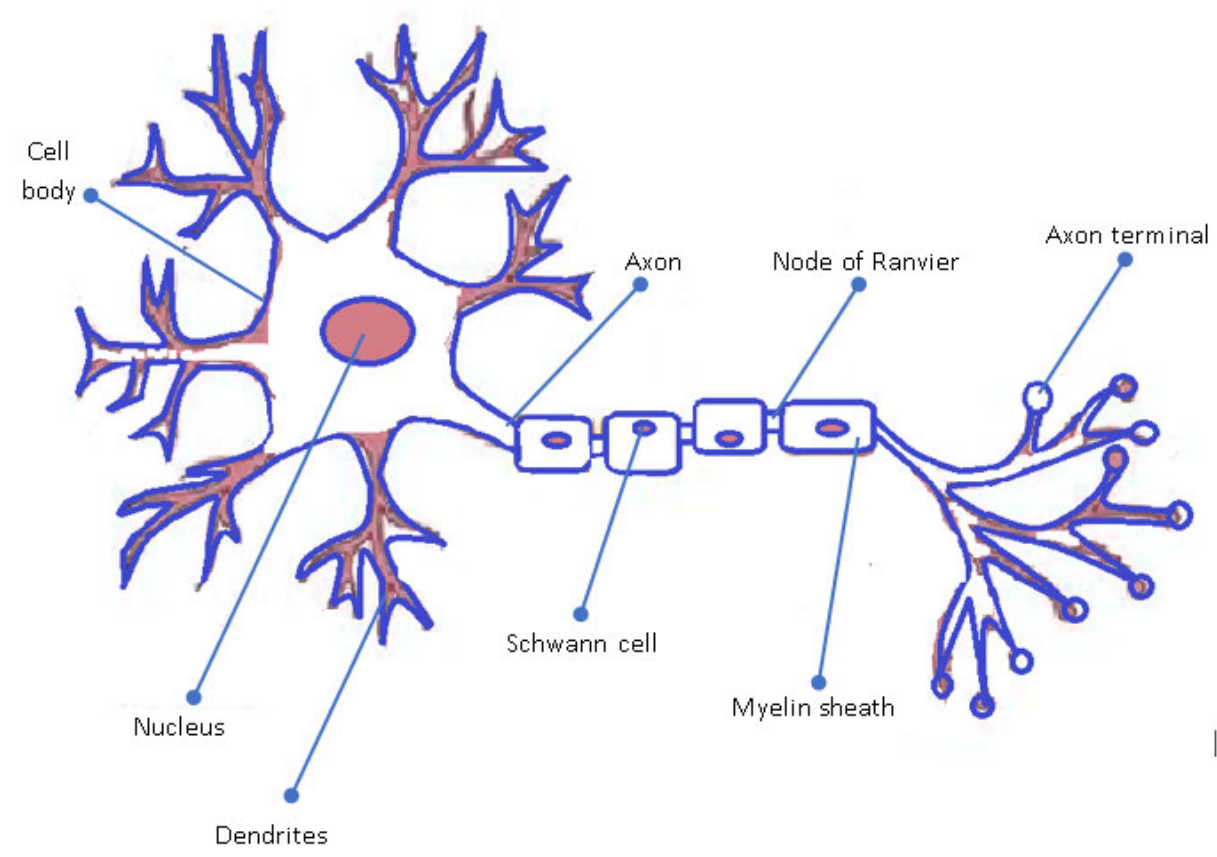

Figure 4. Human brain system. 


\section{HIDDEN LAYER}

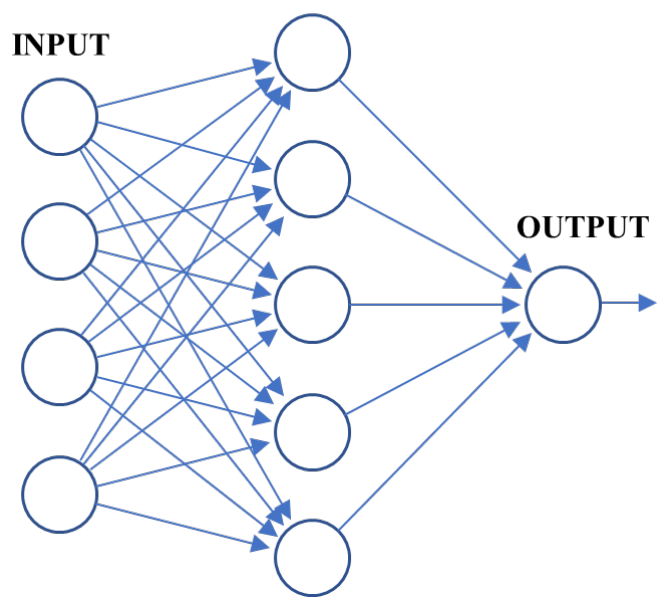

Figure 5. Neural networks.

Therefore, an analogy can be drawn from these similarities. The nodes in human brain are called neurons in neural networks and the connection between cells is called a connection of neurons in the neural networks. There also are assumptions taken to develop neural networks based on human brain system:

- Information processing is conducted at the neurons.

- The connection links of one neuron to another are utilized to pass the signals between them.

- Every connection link has a weight which is used to multiply the signal transmitted.

- An activation function is applied by each neuron to its net input in order to determine its output.

\subsection{Differential Evolution}

Das and Suganthan [14] pointed out why scholars consider DE as an interesting optimization method:

a. DE is more straightforward to implement compared to most other evolutionary algorithms.

b. DE gives away a better performance on broad variety of problems including multimodal, unimodal, separable, non-separable, and so forth.

c. DE has very few control parameters with adaptation rules, and it might increase the performance of the algorithm to a considerable extend without inflicting any significant computational trouble.

d. The capacity difficulty of DE is slight compared to some optimization methods. This feature aids in expanding DE for control of enormous scale and steep optimization difficulties.

DE begins the process with initiating a population that is judged by the cost or fitness function, and the better individuals will proceed to the next generation. Along this process, individuals evolve with mutation and crossover operators; then, this evolution will be pursued until the algorithm achieves a stopping criterion, which is called a selection stage as shown in Figure 6[15].

\subsubsection{Initialization}

At the beginning of the optimization process, an initial population has to be generated. Generally, each decision parameter in every vector of the initial population is given a randomly chosen value from the boundary constraints:

$$
x_{i}{ }_{j}^{0}=a_{j}+\operatorname{rand}_{j} \cdot\left(b_{j}-a_{j}\right)
$$

with rand $_{j}$ defines a uniformly distributed value between $[0,1]$, producing a new number for individually decision parameter. $a_{j}$ and $b_{j}$ are the lower and upper bounds for the jth decision parameter, respectively.

\subsubsection{Mutation}

In the theories of Biology, mutation is known as an abrupt change in the gene characteristic of a chromosome, while in the study, as Das and Suganthan [12] stated, mutation is a process to change the value of a gene with a random element. For each target vector

$$
v_{i}^{G+1}=x_{r 1}^{G}+F *\left(x_{r 2}^{G}-x_{r 1}^{G}\right), r_{1} \neq r_{2} \neq r_{3} \neq i
$$

with randomly chosen indices and $r_{1}, r_{2}, r_{3} \in\{1,2, \ldots, N P\}$.

Consider that these indices has to be different from one another and from the running index $i$ so that $N P$ must be at least four. $F$ is a real number to control the amplification of the difference vector $\left(x_{r 2}{ }^{G}-x_{r 1}{ }^{G}\right)$. The range of $F$ is in $[0,2]$. If a component of a mutant vector goes off the search space, then the value of this component is created anew using (2). 


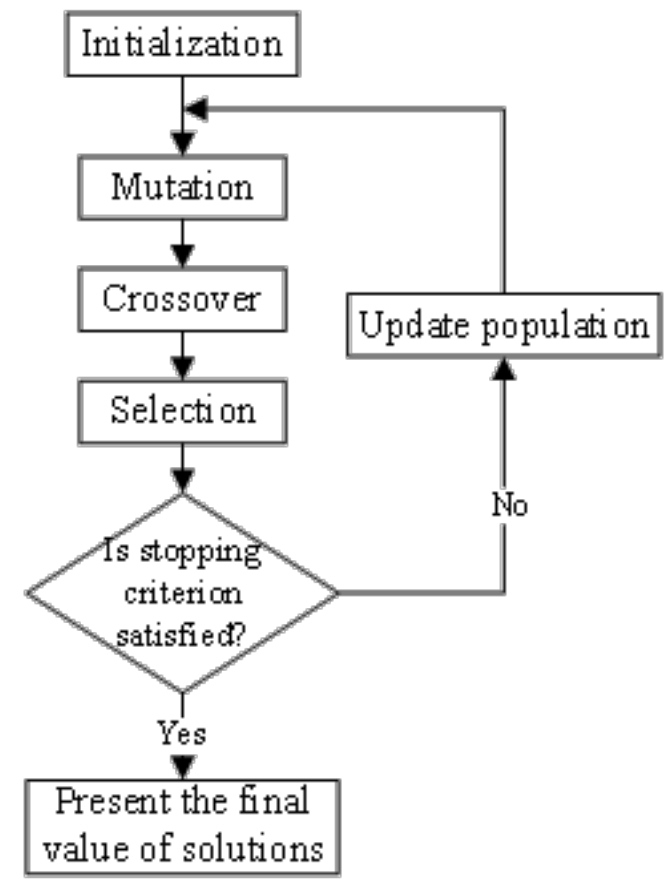

Figure 6. Flowchart for Differential Evolution.

\subsubsection{Crossover}

To increase the potential diversity of the population, a crossover operation comes into use after creating the donor vector through mutation. The donor vector switches its components with the target vector through this operation to form the trial vector [10]. The target vector is mixed with the mutated vector, using the following scheme, to yield the trial vector $\mathrm{u}_{i}{ }^{G+1}$.

$$
\begin{gathered}
u_{i}^{G+1}=v_{i j}^{G+1}, \operatorname{rand}(j) \leq C R \text { or } j=\operatorname{rand} n(i) x_{i j}^{G+1}, \\
\operatorname{rand}(j)>C R \text { or } j \neq \operatorname{rand} n(i)
\end{gathered}
$$

with $j=1,2, \ldots, D, \operatorname{rand}(j) \in[0,1]$ is the $j$-th evaluation of a uniform random generator number. $C R \in[0,1]$ is a constant showing the crossover probability rate, which must be determined by the user. rand $n(i) \in 1,2, \ldots, D$ is a randomly chosen index which ensures that $\mathrm{u}_{i}{ }^{G+1}$ gets at least one element from the mutant vector $\mathrm{v}_{i j}{ }^{G+1}$; or else, no new parent vector would be generated and the population would not change.

\subsubsection{Selection}

DE applies a greedy selection strategy. If only if the trial vector $\mathrm{u}_{i}{ }^{G+1}$ yields a better fitness function value than $\mathrm{x}_{i}{ }^{G}$, then $\mathrm{u}_{i}{ }^{G+1}$ is set to $\mathrm{x}_{i}{ }^{G+1}$. Otherwise, the old vector $\mathrm{x}_{i}^{G}$ is maintained. The selection scheme is as follows:

$$
x_{i}^{G+1}=u_{i}^{G+1}, f\left(u_{i}^{G+1}\right)<f\left(x_{i}^{G}\right) x_{i}^{G}, f\left(u_{i}^{G+1}\right) \geq f\left(x_{i}^{G}\right)
$$

\subsection{Teaching Learning Based Optimization}

Teaching Learning Based Optimization is a metaheuristic method illustrating a natural condition in a class. Rao et al. [16] proposed a study to establish an up-to-date optimization method untied from the algorithm parameters and can answer divergent optimization troubles effectively and efficiently. This new method is called Teaching Learning Based Optimization (TLBO).

The TLBO method shows the influence of guidance from a teacher towards the output of their students in class. The result here is deemed as the grades of the students while the teacher is reckoned as a highly learned person who distributes their knowledge with their students. Rao et al. explained that a good teacher brings out a better mean for the grades of their students. They also stated that a teacher improves the mean of their class in accordance with their capability. Other than that, the quality of the students is determined from the mean value of the population, or in this case is the class. The teacher will put efforts to escalate the quality of their students prior to a point showing that the students need a new teacher of a better level than themselves. The study enunciated that TLBO is divided into two parts. The first is called the 'Teacher Phase,' and in this phase the class students are learning from their teacher. The second phase is called the 'Learner Phase,' which means the students learn from their interactions (Figure 7). 


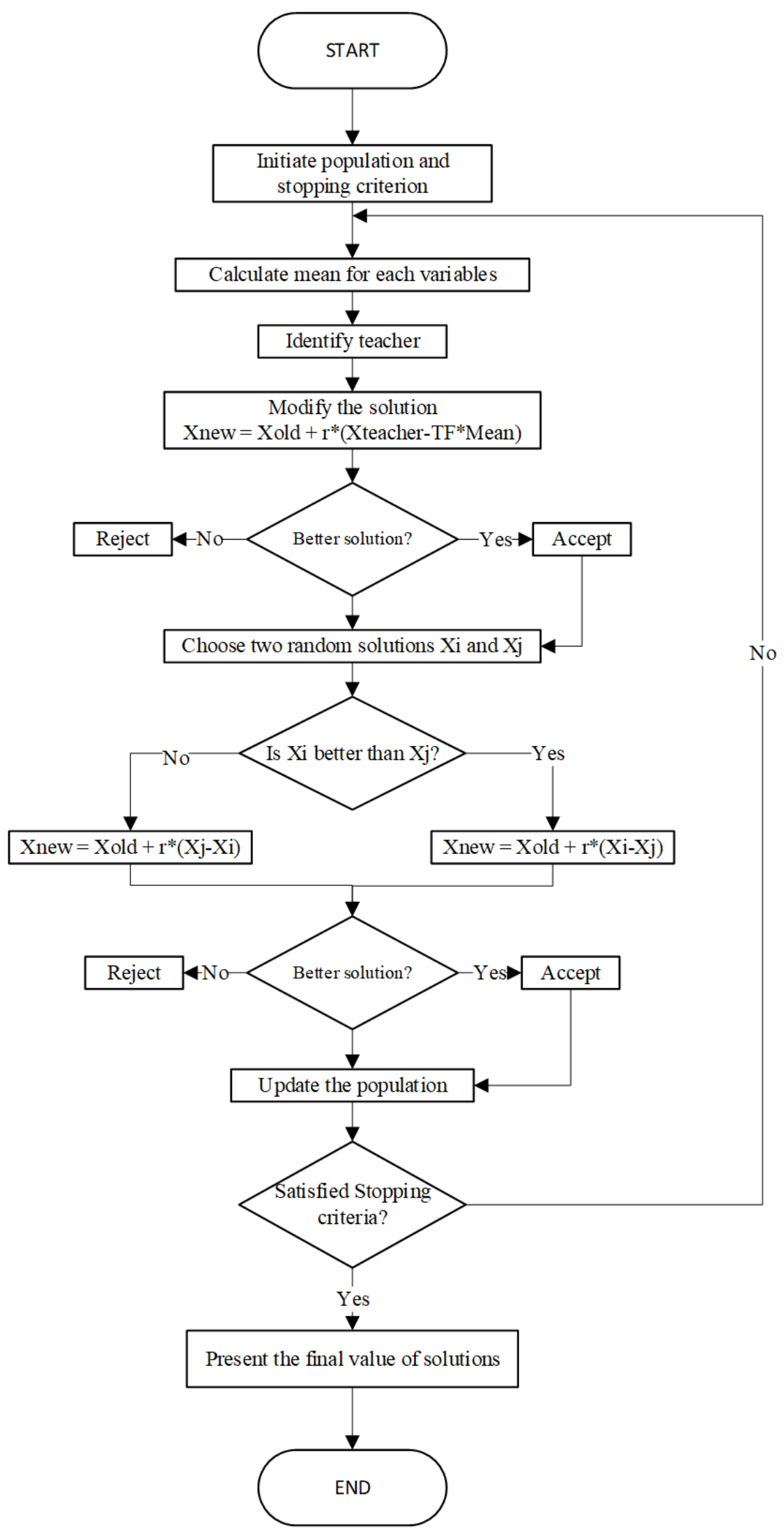

Figure 7. Flow chart for Teaching Learning Based Optimization. 


\subsubsection{Teacher Phase}

Rao et al. [17] stated that a good teacher is the one who can help their students get to their higher level of knowledge and increase the mean of their class from $M_{A}$ to $M_{B}$. But in reality, this is not possible as a teacher can only enhance the mean of their class up to the capability of the class and it depends on many factors. Let $M_{i}$ be the mean and $T_{i}$ be the teacher at any iteration $i$. This $T_{i}$ will try to move mean $M_{i}$ towards its level, hence now the new mean will be $T_{i}$ designated as $M_{n e w}$. The solution is updated according to the difference between the existing and the new mean is given by

$$
\text { Difference_Mean }{ }_{i}=r_{i}\left(M_{\text {new }}-T_{F} M_{i}\right)
$$

with $\mathrm{T}_{F}$ is defined as a teaching factor that decides the value of the mean to be adjusted, and $\mathrm{r}_{i}$ is a random number in the range of $[0,1]$. The value of $\mathrm{T}_{F}$ can either be 1 or 2 which is a heuristic step and decided randomly with the same probability as $\mathrm{T}_{F}=\operatorname{round}[1+\operatorname{rand}(0,1)\{2-1\}]$. Then the following expression is used by the difference to modify the existing solution,

$$
X_{n e w, i}=X_{o l d, i}+\text { Difference_Mean }{ }_{i}
$$

\subsubsection{Learner Phase}

Rao et al. [12] also expressed that students from a class or so-called learners expand their knowledge by two different means: the first one is by input from their teacher, and the second one is by the interaction between themselves. Learners in a class will interact with each other randomly by having discussions, group presentations, formal communications, etc. A learner can learn something new if the other learner has more information or knowledge than them. Learner modification is shown below

For $i=1: P_{n}$

Randomly select two learners $X_{i}$ and $X_{j}$, where $i \neq j$

$N_{\text {new }, i}=X_{o l d, i}+r_{i}\left(X_{i}-X_{j}\right)$

Else

$N_{\text {new }, i}=X_{\text {old }, i}+r_{i}\left(X_{j}-X_{i}\right)$

End If

End For

Accept $X_{n}$ ew if it gives a better function value.

\section{Experimental Method} culation

The following limitations are being used in our cal-

a The BPNN uses one up to 5 hidden layers with 2-10 neurons each, and the learning method is Levenberg Marquardt.

b The same numbers of neurons are used to simplify the topography of the BPNN; hence it will take a shorter time to process.

c The steps used in Differential Evolution are generalized mutation, binomial crossover, and selection.

d TLBO is done with 0 as the lower bound, ten as the upper bound, having a population number of 100 and 100 iterations.

e The stopping criteria for both DE and TLBO are the stage of a lower value (from the previous value) is obtained then gains a convergence value after updating the population as much as the number of iterations.

f The data used in the study is based on research done by the Production Engineering Laboratory of Mechanical Engineering Department, Faculty of Industrial Technology and Engineering Systems ITS in 2019 about the drilling process of GFRP.

$\mathrm{g}$ The used activation functions are hardlim, purelin, logsig, and tansig.

$\mathrm{h}$ The data split of this study is $70 \%, 15 \%$, and $15 \%$ for training, testing, and validating, respectively.

CNC Vertical Machining Center is used to carry out the experiment and since this study is based on a previous research done by Laboratory in 2019, the materials used in that experiment are E-glass GFRP with length of $200 \mathrm{~mm}$, width of $30 \mathrm{~mm}$, and the thickness is $6 \mathrm{~mm}$. The FRP has $0.25 \mathrm{~mm}$ thickness of each ply, hence it has 24 plies. Its tensile modulus, shear modulus, tensile strength, and density are $19 \mathrm{GPa}, 20.5 \mathrm{GPa}, 390 \mathrm{MPa}$, and $1.86 \mathrm{~g} / \mathrm{cm}^{3}$, respectively. The material has two different types of drill geometry called S type which is made of HSS and X type which is made of HSS-cobalt (Figure 8), and each of them is $10 \mathrm{~mm}$ in diameter.

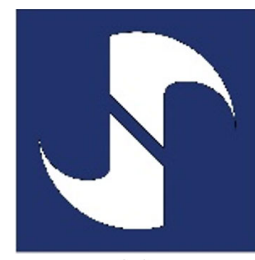

(a)

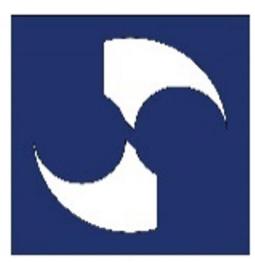

(b)

Figure 8. Drill point geometry (a) S type and (b) X type. 
The measurement tools for thrust force, torque, hole roundness, and hole surface roughness were Kistler 9272 dynamometer, Kistler 972 dynamometer as shown in Figure 9, EC-3D round tester, and Mitutoyo Surftest SJ-310, respectively. The schematic of thrust force and torque measurements can be seen in Figure 10.

The Table 1 shows the experimental process parameters which divided into three levels each, while the experiment was done with some steps as shown in Figure 11 Moreover, the experimental data can be seen in Figure 12 . where R1, R2, and R3 show the replication of the experiment. Figure 11 shows the procedure of this study and it starts with doing literature review, using the data from an experiment of multi-performance optimization in drilling process of GFRP using RSM and BPNN-GA as the experimental data, defining the input and output parameters, modelling the BPNN, then doing the response optimization using DE and TLBO, comparing the results, determining whether the optimization is better, and concluding the study.

The experimental data can be seen in Figure 12 , where R1, R2, and R3 show the replication of the experiment. It includes the thrust force $\left(F_{z}\right)$, torque $\left(M_{z}\right)$, hole roundness $(R)$, and hole surface roughness $(S R)$ data. Every parameter has 18 data and being replicated trice shown as $R 1, R 2$, and $R 3$, thus the total number of the data is 54 for each parameter.

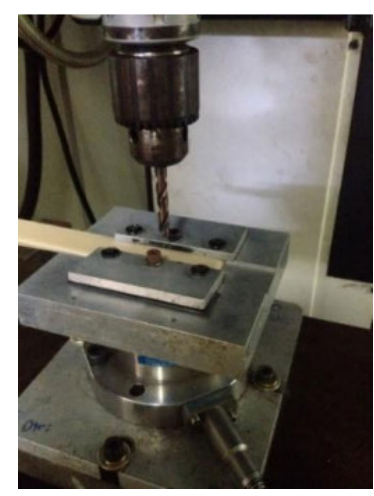

Figure 9. GFRP drilling process using dynamometer Kistler.

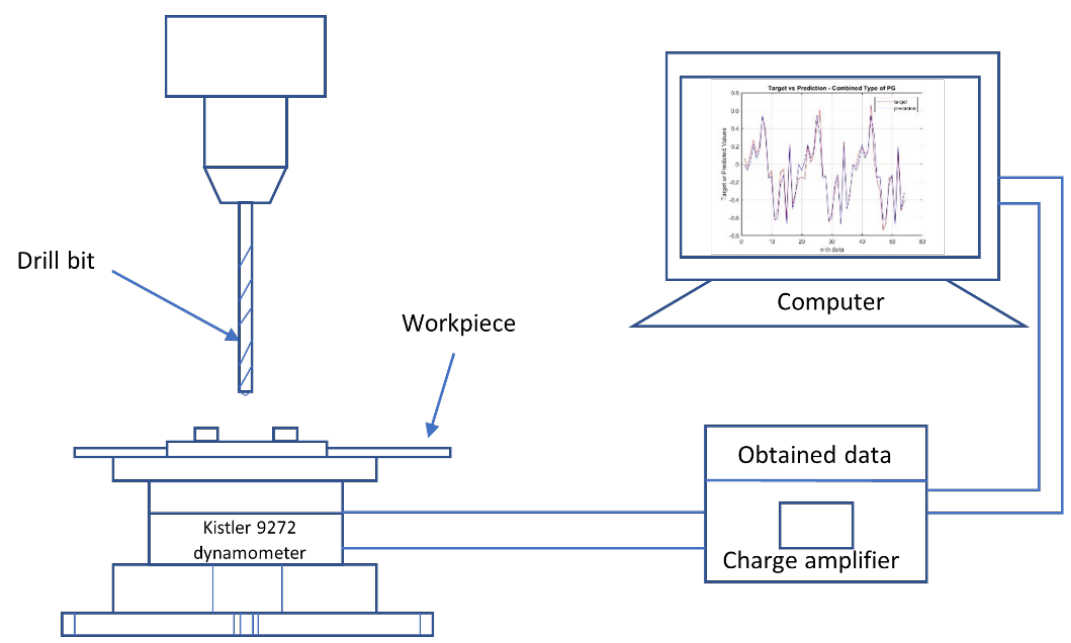

Figure 10. Schematic of thrust force and torque measurements. 
Table 1. Experimental process parameters and their levels.

\begin{tabular}{ccccc}
\hline Parameters & Units & Level 1 & Level 2 & Level 3 \\
\hline Drill point geometry & - & S type & X type & - \\
Drill point angle & degree & 90 & 118 & 135 \\
Feed rate & $\mathrm{mm} / \mathrm{min}$ & 50 & 100 & 150 \\
Spindle speed & $\mathrm{rpm}$ & 2000 & 2500 & 3000 \\
\hline
\end{tabular}

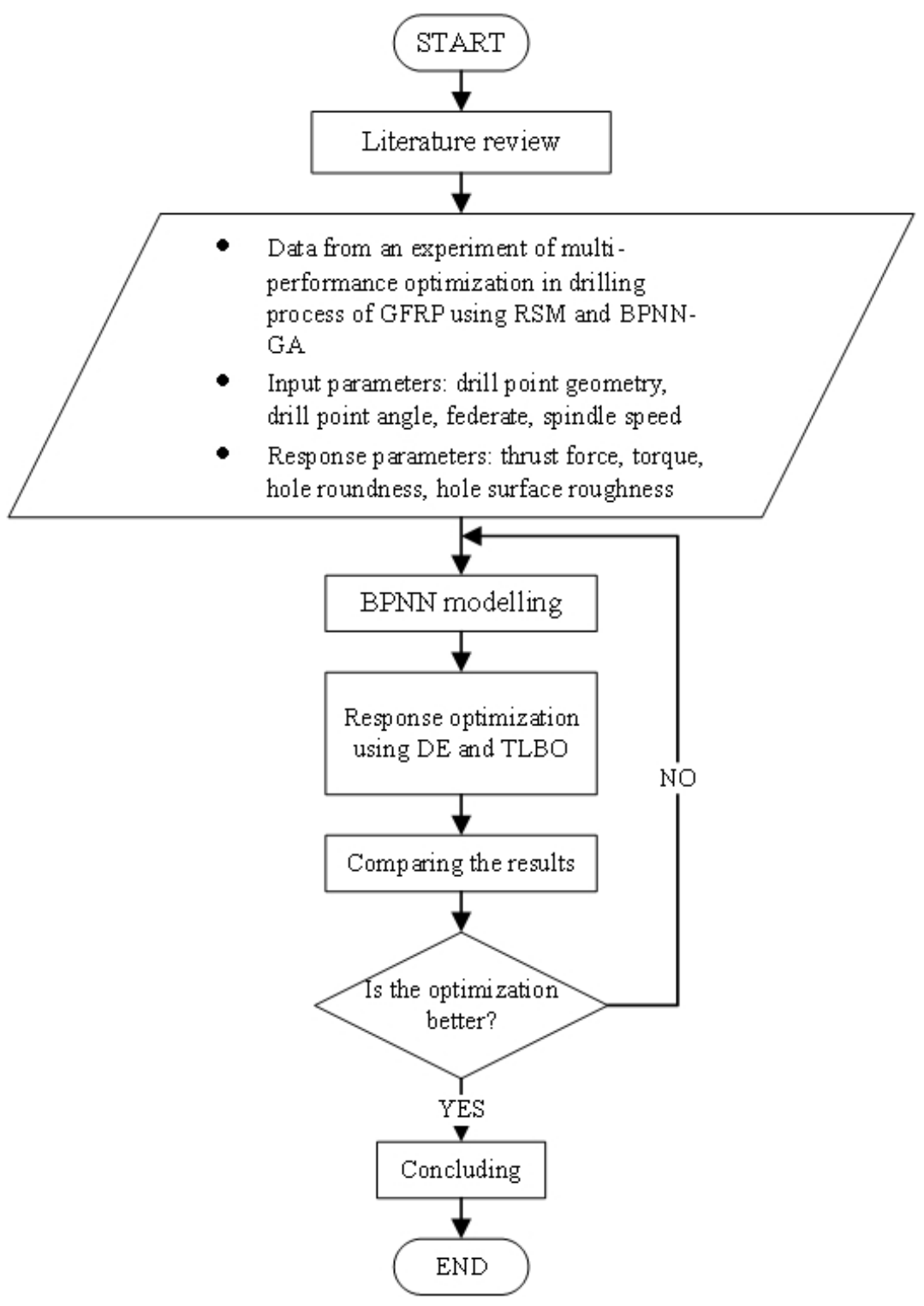

Figure 11. Experimental procedure. 

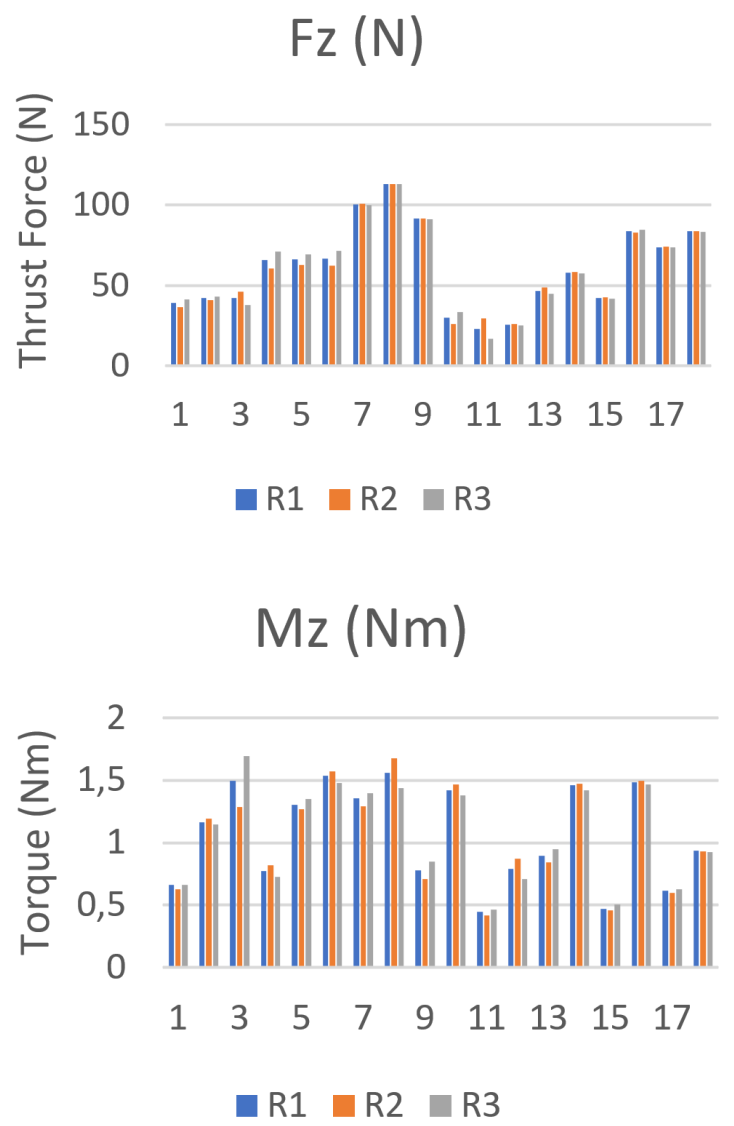
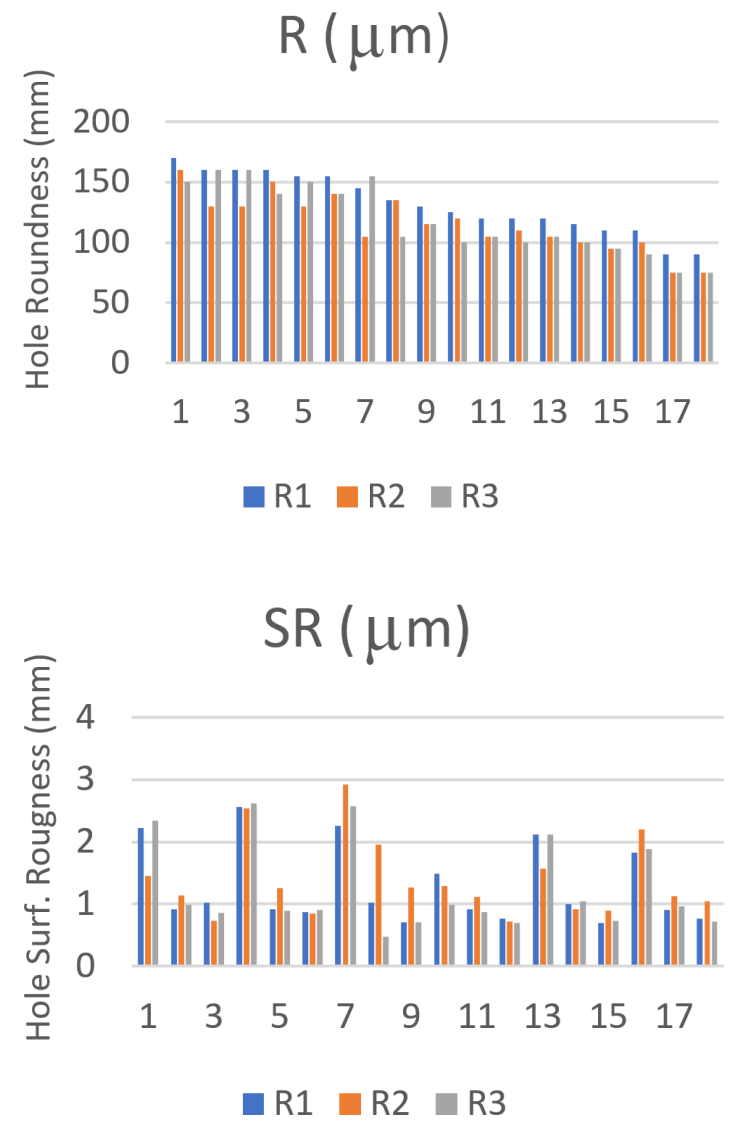

Figure 12. Experimental data.

\section{Results and Discussion}

To determine the predicted responses, this study combines the response parameters by giving them weights 0,25 each and expressed with the following equation called the objective function, which is formulated by the following equation:

$$
\begin{aligned}
\text { Obj.Function } & =(0.25 \times F z)+(0.25 \times M z)+(0.25 \times R) \\
& +(0.25 \times S R)
\end{aligned}
$$

with the phrase Obj. function shows target or the combined response parameters, $\mathrm{Fz}$ is thrust force $(N), \mathrm{Mz}$ is torque $(\mathrm{Nm}), R$ is hole roundness $(\mu \mathrm{m})$, and $S R$ is hole surface roughness $(\mu \mathrm{m})$.

Before entering the neural network training process, a normalization step is done using MATLAB command, namely mapminmax which has $[-1,+1]$ as its range. The normalization can be calculated with the following formulation:

$$
\begin{aligned}
x_{n j} & =\frac{x_{i}-\min _{a}}{\max _{a}-\min _{a}} \cdot\left(\text { newmax }_{a}-\text { newmin }_{a}\right) \\
& + \text { newmin }_{a}
\end{aligned}
$$

with $\mathrm{x}_{n j}$ defines the normalized value of $x$ from $j$-th variable, $x_{i}$ expresses the initial value of $x, \min _{a}$ shows the minimum value of overall data, while $\max _{a}$ shows the maximum value of overall data, newmax $x_{a}$ tells the maximum value of the defined range, and newmin ${ }_{a}$ tells the minimum value of the defined range. The following calculations show an example of expression (9) application,

The calculations carried out the first values from $\mathrm{R}$ variable, with $x_{i}=125, \min _{a}=75, \max _{a}=125$,

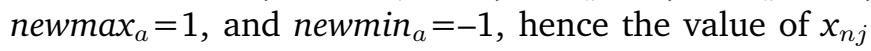
is

$$
\begin{aligned}
x_{n j} & =\frac{125-75}{125-75} \cdot(1-(-1))+(-1) \\
x_{n j} & =\frac{50}{50} \cdot(2)+(-1) \\
x_{n j} & =1
\end{aligned}
$$

After completing the normalization process, the BPNN modeling is being carried out, and this study will show the MSE from each type and the comparison of the target with the predicted values. Figure 13, 14, and 15 show the gained MSE values for each type. 

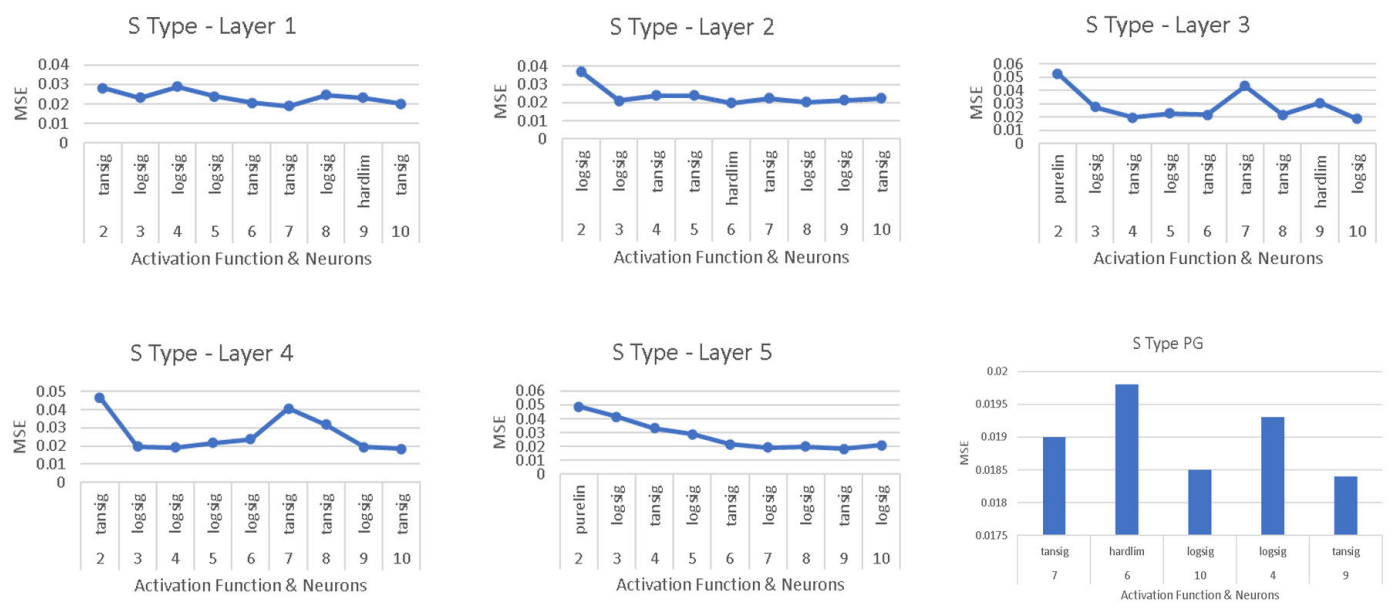

Figure 13. Values of MSE for S Type PG.
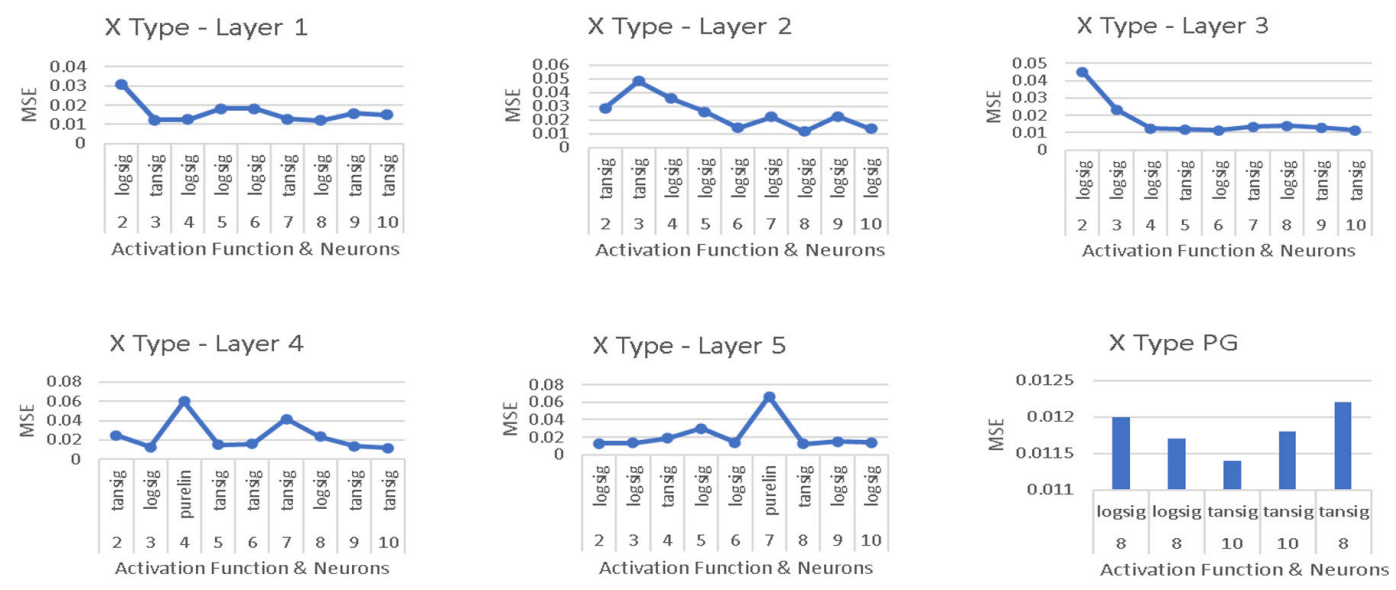

Figure 14. Values of MSE for X Type PG.

Combined Type - Layer 1

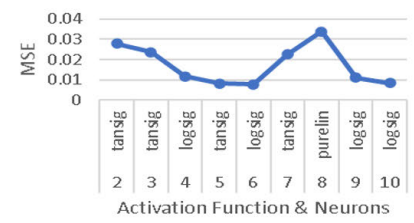

Combined Type - Layer 4

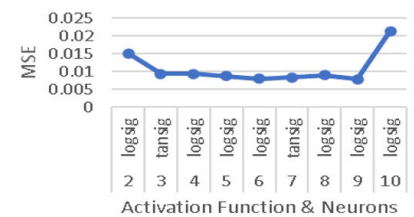

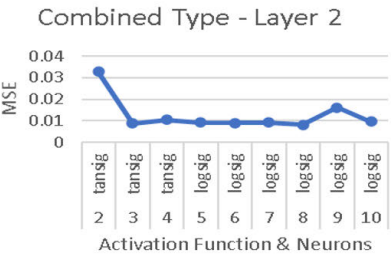

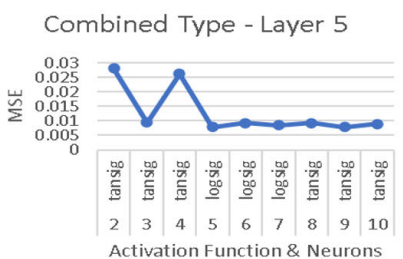

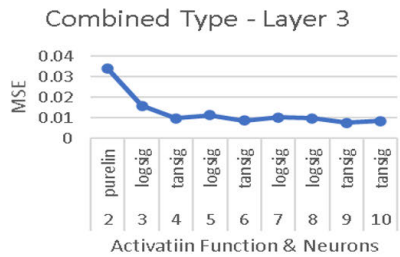

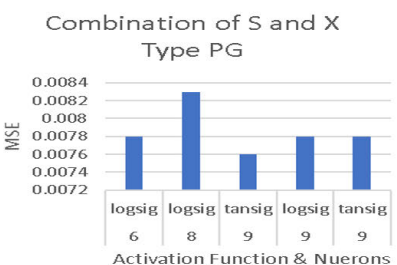

Figure 15. Values of MSE for Combination of S and X Types PG. 
From Figure 13 through Figure 15 it is known that the MSE for S type PG is $0.0184,0.0114$ for the $\mathrm{X}$ type PG, and 0.0076 for the combined type, with the suitable Backpropagation Neural Networks parameters to gain the smallest error of the response prediction are five hidden layers, nine neurons, and using logsig as the activation function for Type S PG, while the parameters for Type X PG are three hidden layers, ten neurons, and using logsig as the activation function, and the parameters for Combination of Type S and X PG are three hidden layers, nine neurons, and using tansig as the activation function. Besides obtaining the MSE values for each type, there are also comparisons between the target numbers with the prediction results, which are shown in Figure 16.

From the predicted values shown in Figure 13 through Figure 15 and Figure 16, it is known that the smallest error occurs in BPNN model with the combination of $S$ and $X$ type PG. However, this model needs a penalty and complex steps. Therefore the used PG types in this optimization experiment in the drilling process for
GFRP are S type and X type PG, separately. After getting the MSE values from the BPNN modelling, the next step is to find the input parameter values based on the optimization using DE and TLBO methods. The results of this optimization need to be denormalized to convert it into original value. The denormalization process applies a simple linear expression to make it easier to be applied to DE and TLBO results. The formulation used in the denormalization is

$$
y=m x+c
$$

with $y$ is the value obtained from the optimization methods, $x$ is the input parameter, while $m$ and $c$ are constants that will be calculated by entering +1 and -1 as the upper bound and lower bound, respectively. The following calculations show the application of expression (10) in finding the best values of input and output parameters, and the one being an example here is the calculation for type S PG in determining the value of its input parameter, PA:

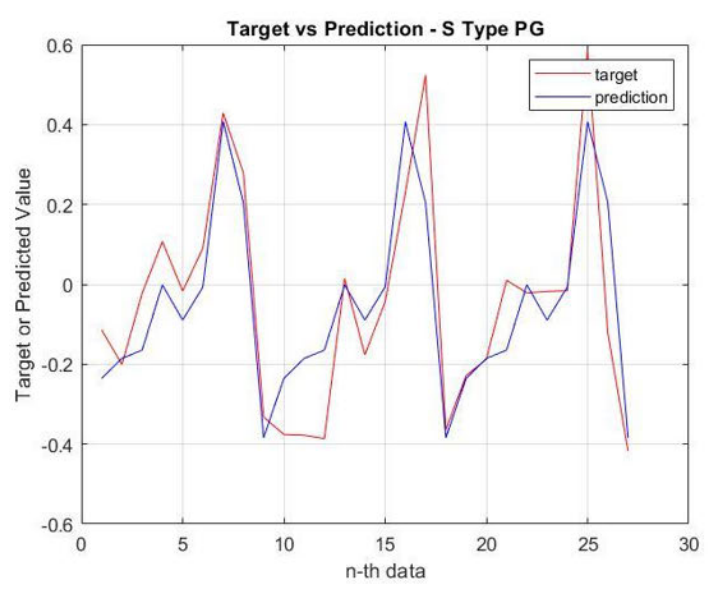

(a)

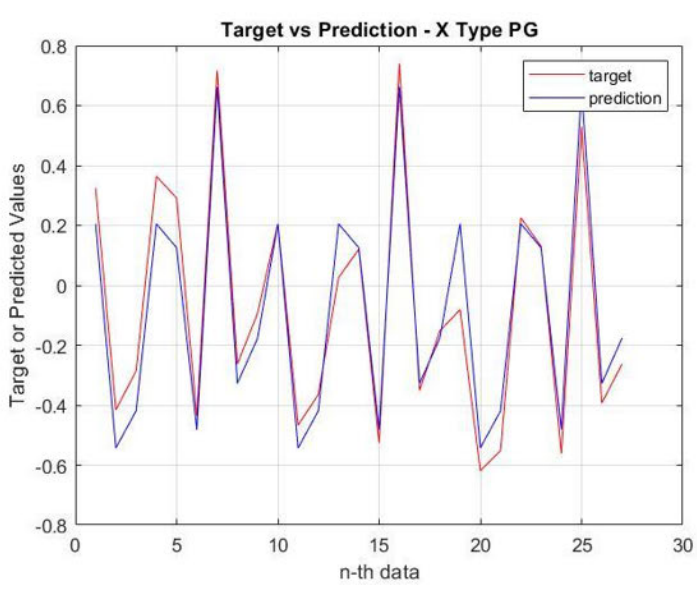

(b)

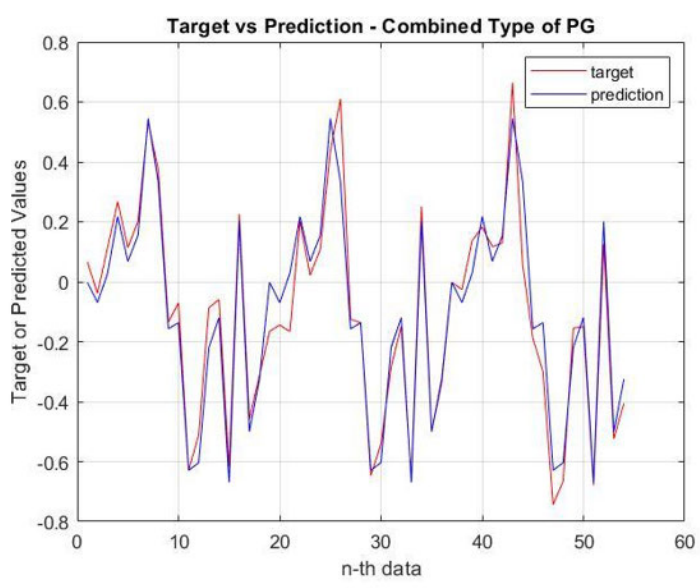

(c)

Figure 16. Comparison of targeted and predicted values of PG (a) S type, (b) X type, (c) Combination of $S$ and X type. 
- Finding the $m$ and $c$ Values for PA

The values of $y=-1$ with $x=90$ and $y=1$ for $x=135$. Those values will be substituted into expression (10) then two expressions will be obtained as the following:

$$
\begin{aligned}
& -1=90 m+c \\
& 1=135 m+c
\end{aligned}
$$

The next step is finding the value of $m$ by subtracting expression (a) to (b) and it will produce expressions (c) to (e) as the following:

$$
\begin{gathered}
-2=-45 m \\
m=0.044444 \\
c=-4.99996
\end{gathered}
$$

- Finding the Value of $x_{1}$ or PA for Type S PG The values of $y=1, m=0.044444$, and $c=$ 4.99996. Those values will be substituted into expression (10) and the value of $x_{1}$ or PA for the type S PG will be known as the following:

$$
\begin{array}{ll}
1 & =x_{1}(0.044444)+(-4.99996) \\
5.99996 & =x_{1}(0.044444) \\
x_{1} & =135
\end{array}
$$

The same process will be applied in determining the input and output parameters for both DE and TLBO methods, which the results are shown in Table 2.

Graphs in Figure 17 show the gained results after doing the optimization using DE, and TLBO methods. Graph (a) uses type S PG and it can be seen that DE method gains values of -0.385702 while TLBO obtains -0.399422 . The graph also shows that TLBO gets the constant number $-0,474519$ at its $2^{\text {nd }}$ iteration whilst DE obtains the constant value of $-0,474519$ at its $3^{\text {rd }}$ iteration. Then graph (b) uses type X PG and it shows that DE obtains the

\begin{tabular}{|c|c|c|c|c|c|c|c|c|c|}
\hline \multirow{2}{*}{ Method } & \multicolumn{4}{|c|}{ Optimum Drilling Parameters } & \multicolumn{4}{|c|}{ Response Parameters } & \multirow{2}{*}{ Iteration } \\
\hline & PG & PA & $f$ & $\mathrm{n}$ & $\mathrm{Fz}$ & $\mathrm{Mz}$ & $\mathrm{R}$ & SR & \\
\hline BPNN-DE & S & 135 & 150 & 2000 & 46,6 & 0,894 & 97 & 1,356 & 3 \\
\hline BPNN-TLBO & S & 135 & 150 & 2000 & 46,6 & 0,894 & 97 & 1,356 & 2 \\
\hline BPNN-DE & $\mathrm{X}$ & 90 & 89.759 & 2841 & 45,9 & 0,8835 & 96,5 & 1,255 & 58 \\
\hline BPNN-TLBO & $\mathrm{X}$ & 90 & 89.754 & 2821 & 45,9 & 0,8835 & 96,5 & 1,255 & 12 \\
\hline
\end{tabular}
number of $-0,552206$ while TLBO gains $-0,556338$. TLBO obtains the constant number of $-0,556730$ at its $12^{\text {th }}$ iteration while DE gains the constant value of $-0,556670$ at its $58^{\text {th }}$ iteration.

The following table shows the comparison the results of DE and TLBO optimization methods:

Table 2. Comparison of optimization results using DE and TLBO

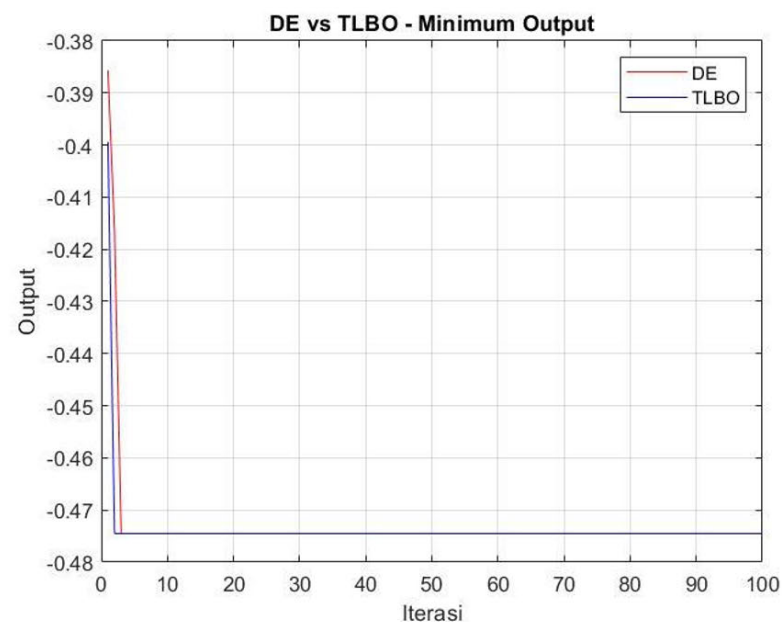

(a)

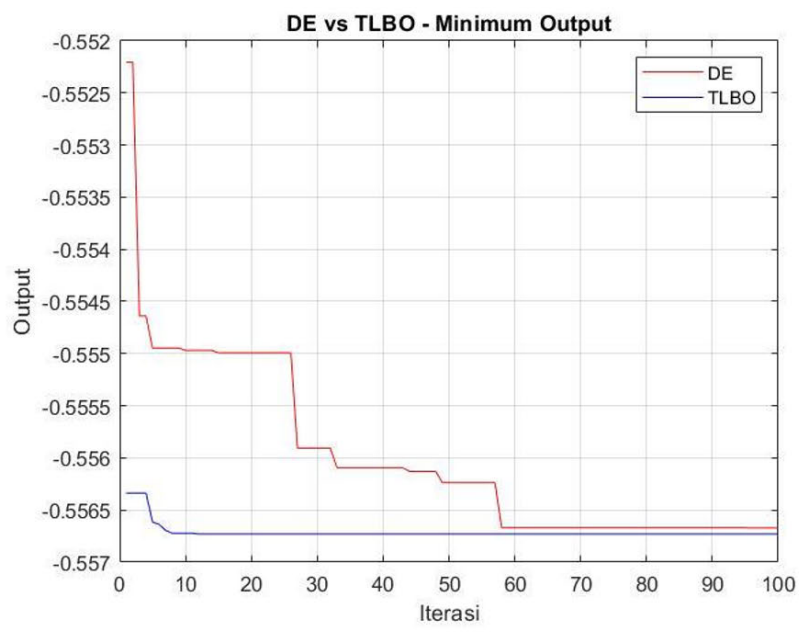

(b)

Figure 17. Comparison of optimization results using DE and TLBO. 
Table 3. The new values of feed rate

\begin{tabular}{|c|c|c|c|c|c|c|c|c|c|}
\hline \multicolumn{10}{|c|}{ X Type } \\
\hline \multirow{2}{*}{$\begin{array}{c}\mathrm{f} \\
(\mathrm{mm} / \mathrm{min})\end{array}$} & \multirow{2}{*}{$\begin{array}{c}\mathrm{n} \\
(\mathrm{rpm})\end{array}$} & \multicolumn{4}{|c|}{$\mathrm{DE}$} & \multicolumn{4}{|c|}{ TLBO } \\
\hline & & $\begin{array}{l}\mathrm{Fz} \\
(\mathrm{N})\end{array}$ & $\begin{array}{c}\mathrm{Mz} \\
(\mathrm{Nm})\end{array}$ & $\begin{array}{c}\mathrm{R} \\
(\mu \mathrm{m})\end{array}$ & $\begin{array}{c}\text { SR } \\
(\mu \mathrm{m})\end{array}$ & $\begin{array}{l}\mathrm{Fz} \\
(\mathrm{N})\end{array}$ & $\begin{array}{c}\mathrm{Mz} \\
(\mathrm{Nm})\end{array}$ & $\begin{array}{c}\mathrm{R} \\
(\mu \mathrm{m})\end{array}$ & $\begin{array}{c}\text { SR } \\
(\mu \mathrm{m})\end{array}$ \\
\hline \multirow{5}{*}{89} & 2841 & 49.87 & 0.95 & 99.46 & 1.43 & 49.87 & 0.95 & 99.46 & 1.43 \\
\hline & 2842 & 49.45 & 0.94 & 99.14 & 1.42 & 49.45 & 0.94 & 99.14 & 1.42 \\
\hline & 2900 & 50.11 & 0.95 & 99.63 & 1.43 & 50.11 & 0.95 & 99.63 & 1.43 \\
\hline & 3000 & 50.22 & 0.95 & 99.71 & 1.44 & 50.22 & 0.95 & 99.71 & 1.44 \\
\hline & 2841 & 50.20 & 0.95 & 99.69 & 1.44 & 50.20 & 0.95 & 99.69 & 1.44 \\
\hline \multirow{3}{*}{90} & 2842 & 50.21 & 0.95 & 99.71 & 1.44 & 50.21 & 0.95 & 99.71 & 1.44 \\
\hline & 2900 & 49.42 & 0.94 & 99.12 & 1.42 & 49.42 & 0.94 & 99.12 & 1.42 \\
\hline & 3000 & 50.71 & 0.96 & 100.07 & 1.45 & 50.71 & 0.96 & 100.07 & 1.45 \\
\hline \multirow{4}{*}{100} & 2841 & 47.82 & 0.91 & 97.94 & 1.38 & 47.82 & 0.91 & 97.94 & 1.38 \\
\hline & 2842 & 50.34 & 0.95 & 99.80 & 1.44 & 50.34 & 0.95 & 99.80 & 1.44 \\
\hline & 2900 & 49.89 & 0.95 & 99.47 & 1.43 & 49.89 & 0.95 & 99.47 & 1.43 \\
\hline & 3000 & 49.63 & 0.94 & 99.28 & 1.42 & 49.63 & 0.94 & 99.28 & 1.42 \\
\hline
\end{tabular}

As it is shown in Table 2, the DE method needs more iterations than TLBO to get its optimum value of the parameters. It is possible to happen because only a few samples lead to being trapped in the local optimum, and the search may not be more expansive. There are only slight differences in DE and TLBO methods as both method has similar optimization results. Besides having decimal values for some parameters, it is necessary to approach these results with a step to find a possible value to be operated by practitioners using the Equation (a) to (e) as in the previous discussion.

The parameters that need to be calculated are feed rate $f$ and spindle speed $n$ with values of 89,90 , $100 \mathrm{~mm} / \mathrm{min}$ and 2841, 2842, 2900, $3000 \mathrm{rpm}$ for $f$ and $n$, respectively. Therefore, the new values of feed rate are shown in the following table.

From Table 3, it can be seen that the smallest response parameters were gained by using $f 100 \mathrm{~mm} / \mathrm{min}$ and $n 2841 \mathrm{rpm}$ for DE and TLBO methods with X type PG.

\section{Conclusions}

This study results suggest that DE method gains higher values than TLBO using both Type $S$ and Type $X$ PG. On the other hand, TLBO is able to obtain the constant number faster than DE for both Type $S$ and Type $\mathrm{X}$ PG. The contents of this paper show that optimization in the drilling process of GFRP and the application of DE and TLBO will continue to expand in a multi-disciplinary study in the years to come. However, as the data used in this study was limited, the optimization applying DE and TLBO methods could not achieve their best results. Therefore, the future experiment needs more data to make the prediction processed by BPNN becomes more accurate.

\section{References}

[1] V. J. Worner, "Use of glass fibre reinforced polymer (GFRP) reinforcing bars for concrete bridge decks," Master thesis, 2015.

[2] S. Reddy and R. Mandava, "Aero space applications of GFRP composites," Review, pp. 10-14, Aug. 2017.

[3] F. Becker, C. Hopmann, F. Italiano, and A. Girelli, "Fatigue testing of GFRP materials for the application in automotive leaf springs," Procedia Structural Integrity, vol. 19, pp. 645-654, 2019.

[4] Ephraim M.E., Adetiloye A., and Harcourt P., "Mechanical properties of glass fibre reinforced polymer based on resin from recycled plastic," IJSER, vol. 6, pp. 145-152, Mar. 2015.

[5] American Concrete Institute (ACI) Committee, "Guide for the design and construction of externally bonded FRP systems for strengthening concrete structures," American Concrete Institute, 2017.

[6] M. Robert, P. Cousin, and B. Benmokrane, "Durability of GFRP reinforcing bars embedded in moist concrete," Journal of Composites for Construction, vol. 13, pp. 66-73, Apr. 2009.

[7] G. Das and P. Das, "Cutting forces in drilling operation: measurement and modeling for medium-scale manufacturing firms," International Journal of Computer Applications, vol. 121, pp. 11-7, July 2015.

[8] B. O. P. Soepangkat, R. Norcahyo, M. K. Effendi, and B. Pramujati, "Multi-response optimization of carbon fiber reinforced polymer (CFRP) drilling using back propagation neural network-particle swarm 
optimization (BPNN-PSO)," Engineering Science and Technology, an International Journal, vol. 23, no. 3, pp. 700-713, 2020.

[9] K. S. Prasad and G. Chaitanya, "Analysis of delamination in drilling of GFRP composites using taguchi technique," Materials Today: Proceedings, vol. 18, pp. 3252-3261, 2019.

[10] Cusabio, "Neuron cell," Cusabio, https://www.cusabio.com/Cell-Marker/NeuronCell.html (accessed on 14 August 2021).

[11] D. B. Marques, A. O. B. Filho, A. R. S. Romariz, I. M. A. Viegas, D. A. Luz, A. K. B. Filho, S. Labidi, and A. S. Ferraudo, "Recent developments on statistical and neural network tools focusing on biodiesel quality," International Journal of Computer Science and Application (IJCSA), vol. 3, pp. 97-110, Aug. 2014.

[12] U. A. Khashaba, "Drilling of polymer matrix composites: a review," Journal of Composite Materials, vol. 47, pp. 1817-1832, 2013.

[13] B. O. P. Soepangkat, R. Norcahyo, M. K. Effendi, and B. Pramujati, "Multi-response optimization of carbon fiber reinforced polymer (CFRP) drilling using back propagation neural network-particle swarm optimization (BPNN-PSO)," Engineering Science and Technology, an International Journal, vol. 23, pp. 700713, Nov. 2019.

[14] S. Das and P. N. Suganthan, "Differential evolution: A survey of the state-of-the-art," IEEE Transactions On Evolutionary Computation, vol. 15, pp. 4-31, Feb. 2011.

[15] H. S. Noghabi, H. R. Mashhadi, and K. Shojaei, "Differential evolution with generalized mutation operator for parameters optimization in gene selection for cancer classification," Neural and Evolutionary Computing, Oct. 2015.

[16] R. V. Rao, V. J. Savsani, and D. P. Vakharia., "Teaching-learning-based optimization a novel method for constrained mechanical design optimization problems," Computer-Aided Design, vol. 43, pp. 303-315, Dec. 2011.

[17] R. V. Rao, V. J. Savsani, and D. P. Vakharia., "Teaching-learning-based optimization: An optimization method for continuous non-linear large-scale problems," Information Sciences, pp. 1-15, Aug. 2011.
[18] K. Kalita, P. K. Mallick, A. Bhoi, and R. K. Ghadai, "Optimizing drilling induced delamination in GFRP composites using genetic algorithm \& particle swarm optimisation," Advanced Composites Letters, vol. 27, pp. 1-9, Jan. 2018.

[19] M. A. Habib, M. A. U. Patwari, A. Jabed, and M. N. Bhuiyan, "Optimization of surface roughness in drilling of GFRP composite using harmony search algorithm," International Journal of Mechanical Engineering and Robotics Research, vol. 5, pp. 311-316, Oct. 2016.

[20] Z. Botak, K. Pisačić, M. Horvat, and D. Mađerić, "The influence of drill point geometry on tool life," Tehnički glasnik, vol. 12, no. 1, pp. 1-4, 2018.

[21] D. Kumar, K. K. Singh, and R. Zitoune, "Experimental investigation of delamination and surface roughness in the drilling of GFRP composite material with different drills," Advanced Manufacturing: Polymer \& Composites Science, pp. 47-56, 2016.

[22] J. Wells, "To the point: Understanding how a drill point's geometric features work together helps users optimize their drilling operations," CUTTING TOOL ENGINEERING Magazine, https://www.ctemag.com/sites/www.ctemag.com/files /archive pdf/0508-Geometry.pdf (accessed on 20 May 2021), vol. 57, Aug. 2005.

[23] S. O. Ismail, H. N. Dhakal, E. Dimla, and I. Popov, "Recent advances in twist drill design for composite machining: A critical review," Journal of Engineering Manufacture, pp. 1-16, 2016.

[24] Q. Meng, K. Zhang, H. Cheng, S. Liu, and S. Jiang, "An analytical method for predicting the fluctuation of thrust force during drilling of unidirectional carbon fiber reinforced plastics," Journal of Composite Materials, vol. 49, no. 6, pp. 699-711, 2015.

[25] B. S. Kumar, N. Baskar, and K. Rajaguru, "Drilling operation: A review," Materials Today: Proceedings, pp. 926-933, 2020.

[26] A. J. Haleel, "Optimization drilling parameters of aluminum alloy based on taguchi method," AlKhwarizmi Engineering Journal, vol. 14, pp. 14-21, June 2018.

[27] D. Kumar, K. K. Singh, and R. Zitoune, "Experimental investigation of delamination and surface roughness in the drilling of GFRP composite material with different drills," Advanced Manufacturing: Polymer \& Composites Science, vol. 2, pp. 44-56, 2016. 